\title{
PENGARUH DIAMETER DAN JUMLAH PAKU TERHADAP KEKUATAN SAMBUNGAN GESER GANDA BALOK KAYU NANGKA (Artocarpus heterophyllus) dan RASAMALA (Altingia excelsa Noronha) DENGAN PELAT BAJA
}

The Effect of Diameter and Number of Nails to Double Shear Connection Strength of Nangka (Artocarpus heterophyllus) and Rasamala (Altingia excelsa Noronha) Species with Steel Side Plates

Sucahyo Sadiyo ${ }^{\bowtie}$ dan Emma Yusrina Wulandari

Departemen Hasil Hutan Fakultas Kehutanan, Institut Pertanian Bogor, Kampus Darmaga, Bogor

\begin{abstract}
The application of nail connection for part of the structural construction in Indonesia is still become the main choice. Connection type that must be counted on seriously for structural construction, are tension, shear and momen connection. Nangka wood is a type of woods that available in sawing or community woods work around Bogor. Rasamala is endemic and unique woods from West Java. Nails as connection are cheap, available and workable. This research objective is to investigate the effect of diameter and amount of nails to double shear connection strength on two type of woods. The results showed that the increase of diameter and amount of nail will rise the capacity of total allowable load per shear plane (RT) or double shear connection strength of nangka woods and rasamala-steel plate, but this phenomena is different for allowable load capacity per nail per shear plane $(\bar{R})$ for both of that type. Design value for nangka wood based on diameter size 4,1;5,2 and 5,5 $\mathrm{mm}$ are $261 ; 358$ and $365 \mathrm{~kg}$ respectively, and for rasamala wood the design value is sligthly low, which is $227 ; 311$ and $321 \mathrm{~kg}$ respectively. The minimum value becomes fundamental for determining design value of total allowable load per shear plane connection (RT) based on amount of nail (4-10), which is determined by multiply the value of certain type woods with amount of nails used.
\end{abstract}

Key words: double shear, displacement, allowable load per nail per shear plane $(\bar{R})$, total allowable load per shear plane (RT)

\section{PENDAHULUAN}

Kayu telah lama memegang peranan penting dalam kehidupan manusia, baik sebagai bahan bangunan maupun untuk keperluan lainnya. Seiring meningkatnya laju pembangunan, kebutuhan akan kayu terus meningkat dari tahun ke tahun. Hal ini menyebabkan banyaknya kayu berdiameter kecil digunakan sebagai bahan bangunan. Akibat keterbatasan ukuran panjang kayu khususnya untuk bahan bangunan sehingga diperlukan suatu sambungan pada batang-batang kayu untuk bisa mencapai bentang struktur yang dikehendaki.

Keberhasilan suatu kekuatan sambungan salah satunya ditentukan oleh efektifitas suatu alat

\footnotetext{
Diterima: 25 September 2011; Disetujui: 14 Desember 2011

$\square$ Penulis korespondensi (corresponding author): sucahyoss@gmail.com
}

sambung. Menurut Suryokusumo (1984), salah satu faktor yang mempengaruhi kekuatan sambungan adalah keadaan alat sambung. Alat sambung paku sering dijumpai pada struktur dinding, lantai dan rangka dalam bentuk dan ukuran yang bermacammacam. Diameter paku dan jumlah paku dapat digunakan sebagai variabel untuk melihat dan menduga besarnya beban yang bekerja per alat sambung (paku) pada suatu sambungan. Pendugaan besar beban yang mampu bekerja pada tiap alat sambung dapat dilakukan pada kayu-kayu yang banyak digunakan dan diperdagangkan di masyarakat.

Penelitian ini bertujuan untuk mengetahui pengaruh diameter dan jumlah paku terhadap kekuatan sambungan double shear kayu Nangka (A. heterophyllus) dan atau Rasamala (A. excelsa Noronha) dengan pelat baja. 


\section{BAHAN DAN METODE}

Penelitian ini dilaksanakan selama kurang lebih dua bulan, dimana pembagian waktu untuk setiap kegiatan di mulai dari penyiapan bahan dilakukan kurang lebih satu bulan dan analisa bekas pengujian contoh uji kekuatan sambungan double shear (penelitian Yeyet, 2008) yang dilakukan secara grafis membutuhkan waktu selama kurang lebih satu bulan. Penelitian ini dilaksanakan di Bagian Peningkatan Mutu Hasil Hutan dan Bagian Rekayasa dan Desain Bangunan Kayu, Fakultas Kehutanan IPB, Bogor.

\section{Bahan dan Alat}

Bahan penelitian yang digunakan adalah hasil lanjutan dari penelitian Yeyet (2008) berupa contoh uji sambungan kayu double shear tiga jenis kayu (Sengon, Nangka, dan Rasamala) menurut berbagai diameter dan jumlah paku. Dalam penelitian ini ditetapkan hanya dua jenis contoh uji sambungan kayu yaitu 72 buah terdiri dari 36 buah sambungan kayu Nangka dan 36 buah sambungan kayu Rasamala. Bahan yang digunakan yaitu kayu Nangka ( $A$. heterophyllus) dan kayu Rasamala ( $A$. Excelsa Noronha).

Alat-alat yang digunakan dalam penelitian adalah gergaji mesin, gergaji zig saw, golok dan gerinda. Alat-alat ukur yang digunakan dalam menunjang penelitian meliputi kaliper, kertas milimeter block, penggaris, alat tulis, kalkulator, dan komputer.

\section{Metode Penelitian}

\section{Persiapan Contoh Uji}

Contoh uji dalam penelitian ini adalah alat sambung paku yang diperoleh dari hasil lanjutan dari penelitian Yeyet (2008). Contoh uji yang merupakan sambungan double shear balok kayu-pelat baja tersebut pada dasarnya terdiri dari kombinasi antara jumlah paku $(4,6,8$, dan 10 batang) dengan diameter paku (4,1; 5,2 dan 5,5 mm).

Dengan demikian setelah terkumpul sejumlah 72 sambungan dilakukan pembelahan contoh uji sambungan kayu untuk mengeluarkan paku dari balok kayu utamanya. Dari bentuk kerusakan paku yang terjadi saat menerima beban pada sesaran 5 $\mathrm{mm}$ kemudian dapat ditentukan dan dihitung momen maksimumnya. Dari setiap contoh uji sambungan double shear yang berjumlah 3 kali ulangan, dipilih
3 buah paku dari setiap ulangan tersebut yang memiliki perubahan bentuk yang relatif sama untuk ditentukan nilai momen maksimumnya.

\section{Pengujian Contoh Uji}

Perhitungan nilai ketahanan lateral atau kekuatan double shear (tampang dua) ini menggunakan pelat baja dengan alat sambung (paku) dalam penelitian ini digunakan formula atau rumus umum (Timber Engineering, 2003) sebagai berikut:

1. $R=0.5 f_{h^{\prime} 2} t_{2} d$, apabila kerusakan terjadi pada balok kayu sedangkan paku tidak mengalami kerusakan, dan

2. $R=\sqrt{2} \sqrt{M_{y} f_{h \cdot 2} d}$ Apabila balok kayu dan paku mengalami kerusakan; dimana $\mathrm{R}$ kapasitas beban atau kekuatan sambungan double shear per paku per bidang geser, $M_{y}$ momen yang terjadi pada paku, $\mathrm{f}_{\mathrm{h} .2}$ kekuatan melekat atau mengikat paku pada balok kayu dan diameter paku.

Besarnya rata-rata kapasitas beban ijin per paku per bidang geser $(\bar{R})$ ditentukan dengan rumus:

Besarnya kapasitas beban ijin total per bidang geser (RT) ditentukan dengan rumus:

$$
\bar{R}=\frac{R}{n_{s}}
$$

Dimana:

$R=$ kapasitas beban per paku per bidang geser $(\mathrm{kg})$

$\bar{R}=$ kapasitas beban ijin per paku per bidang geser $(\mathrm{kg})$

$R T=$ kapasitas beban ijin total per bidang geser $(\mathrm{kg})$

$n=$ jumlah paku (batang)

$n_{s}=$ faktor keamanan sambungan $(2,75)$

\section{Analisis Data}

Terdapat 2 (dua) faktor utama, diantaranya faktor $A$ (diameter paku) yang terdiri atas tiga taraf yaitu 4,1 $\left(A_{1}\right), 5,2\left(A_{2}\right)$, dan $5,5 \mathrm{~mm}\left(A_{3}\right)$ dan faktor $B$ (jumlah paku) yang terdiri atas empat taraf yaitu $4\left(B_{1}\right), 6\left(B_{2}\right), 8\left(B_{3}\right)$, dan 10 buah $\left(B_{4}\right)$. Model yang digunakan untuk rancangan ini adalah sebagai berikut:

$Y_{i j k}=\mu+A_{i}+B_{j}+(A B)_{i j}+\varepsilon_{i j k}$

Dimana:

$Y_{i j k}=$ Nilai pengamatan pada diameter paku 
(faktor A) taraf ke-i dan jumlah paku (faktor B) taraf ke-j, dan ulangan ke-k

$\mu=$ Rataan umum

$A_{i}=$ Pengaruh diameter paku ke-i

$B_{.}=$Pengaruh jumlah paku ke-j

$(A B)_{i j}=$ Komponen interaksi diameter paku dan jumlah paku

$\varepsilon_{i \mathrm{j} k}=$ Pengaruh acak menyebar normal (pengaruh acak pada diameter paku ke-i, jumlah paku ke-j, dan ulangan ke-k)

Data hasil penelitian diolah dengan menggunakan program SAS (Statistic Analysis System) p6.12. Apabila faktor utama atau interaksi antar faktor utama berbeda nyata pada tingkat kepercayaan $95 \%$, maka pengolahan dan analisis data dilanjutkan dengan menggunakan uji Duncan. Pengujian ini dilakukan dengan melihat perbedaan pengaruh tiap faktor maupun kombinasi perlakuan.

\section{HASIL DAN PEMBAHASAN}

\section{Kekuatan Sambungan Double Shear Kayu Nangka}

\section{Kapasitas beban ijin per paku per bidang geser}

Sebaran rataan kapasitas beban ijin per paku per bidang geser $(\bar{R})$ dan kapasitas beban ijin total per bidang geser (RT) kayu nangka disajikan pada Tabel 1 dan Tabel 2. Tabel 1 memperlihatkan bahwa semakin besar diameter paku yang digunakan semakin besar pula nilai kekuatan double shear atau kapasitas beban ijin per paku per bidang geser $(\bar{R})$, kecuali untuk pemakaian 6 batang paku nilainya relatif tidak berbeda. Berbeda menurut jumlah paku, dimana makin besar jumlah paku yang digunakan justeru terdapat tendensi makin menurun nilai untuk setiap diameter paku walaupun pada pemakaian 10 batang terjadi peningkatan kembali nilai.

Hasil analisis nilai rataan kayu nangka pada sesaran $5 \mathrm{~mm}$ menunjukkan bahwa interaksi antara faktor diameter paku dengan jumlah paku memberikan pengaruh nyata terhadap nilai, dimana $F_{\text {hitung }}(3,27)>F_{\text {tabel }}(2,508)$ pada selang kepercayaan $95 \%$.

Hasil uji lanjut Duncan menjelaskan bahwa perlakuan $A_{3} B_{1}$ (diameter paku $5,5 \mathrm{~mm}$ dengan jumlah paku 4 batang) menghasilkan nilai paling tinggi yaitu $475,2 \mathrm{~kg}$, sedangkan perlakuan $A_{1} B_{3}$ (diameter paku $4,1 \mathrm{~mm}$ dengan jumlah paku 8 batang) menghasilkan nilai paling rendah yaitu $261,0 \mathrm{~kg}$. Hal ini terjadi karena pemakaian paku berdiameter kecil cenderung akan menyebabkan tingginya perlemahan yang terjadi pada sambungan sehingga kerusakan pada paku ukuran kecil ini tinggi, sebagai akibat lebih langsing atau kecilnya luas penampang paku yang menerima beban atau gaya geseran.

Untuk keperluan disain bangunan dengan tujuan keamanan struktur maka nilai yang digunakan adalah nilai minimun untuk setiap ukuran diameter paku. Pada Tabel 1 dapat dilihat bahwa nilai minimum untuk setiap ukuran diameter paku berbeda menurut pamakaian jumlah paku. Pada diameter paku terkecil $(4,1 \mathrm{~mm})$ diperoleh minimum saat pemakaian 8 batang paku, dan untuk diameter 5,2 dan $5,5 \mathrm{~mm}$ nilai minimumnya dicapai pada 10 batang paku.

\section{Kapasitas beban ijin total per bidang geser}

Pada Tabel 2 jelas terlihat adanya kecenderungan umum dimana semakin besar ukuran diameter dan jumlah paku yang digunakan maka semakin besar pula beban ijin total per bidang geser (RT) kayu nangka. Fenomena beban ijin total ini berbeda dengan fenomena sebaran nilai .

Hasil analisis ragam memperlihatkan bahwa interaksi antara diameter paku (A) dan jumlah paku (B) memberikan pengaruh yang sangat nyata terhadap nilai RT kayu nangka pada sesaran 5 mm dimana $F_{\text {hitung }}(6,35)>F_{\text {tabel }}(2,508)$ pada selang kepercayaan $95 \%$ dan $\mathrm{F}_{\text {hitung }}(6,35)>\mathrm{F}_{\text {tabel }}(3,667)$ pada selang kepercayaan $99 \%$.

Tabel 1. Nilai rata-rata $\bar{R}$ kayu nangka berdasarkan diameter dan jumlah paku (kg)

\begin{tabular}{cccccc}
\hline \multirow{2}{*}{$\begin{array}{c}\text { Diameter paku } \\
(\mathrm{mm})\end{array}$} & 4 & 6 & \multicolumn{4}{c}{ Jumlah paku (buah) } & Rata-rata \\
\cline { 2 - 5 } & 345 & 381 & 261 & 10 & 326 \\
5,1 & 405 & 372 & 363 & 319 & 375 \\
5,2 & 475 & 382 & 365 & 358 & 409 \\
5,5 & 408 & 378 & 330 & 415 & 364 \\
Rata-rata & & & & \\
\hline
\end{tabular}


Tabel 2. Nilai RT kayu nangka berdasarkan diameter dan jumlah paku (kg)

\begin{tabular}{|c|c|c|c|c|c|}
\hline \multirow{2}{*}{$\begin{array}{l}\text { Diameter paku } \\
(\mathrm{mm})\end{array}$} & \multicolumn{4}{|c|}{ Jumlah paku (buah) } & \multirow{2}{*}{ Rata-rata } \\
\hline & 4 & 6 & 8 & 10 & \\
\hline 4,1 & 1.379 & 2.287 & 2.086 & 3.189 & 2.235 \\
\hline 5,2 & 1.620 & 2.231 & 2.906 & 3.583 & 2.585 \\
\hline 5,5 & 1.901 & 2.290 & 2.921 & 4.146 & 2.815 \\
\hline Rata-rata & 1.633 & 2.269 & 2.638 & 3.639 & \\
\hline
\end{tabular}

Uji lanjut Duncan memperlihatkan perlakuan $\mathrm{A}_{3} \mathrm{~B}_{4}$ (diameter paku $5,5 \mathrm{~mm}$ dengan jumlah paku 10 batang) menghasilkan nilai RT paling tinggi yaitu $4.146 \mathrm{~kg}$, sedangkan perlakuan $A_{1} B_{1}$ (diameter paku $4,1 \mathrm{~mm}$ dengan jumlah paku 4 batang) menghasilkan nilai RT paling rendah $1.379 \mathrm{~kg}$. Hal ini menegaskan semakin meningkat penggunaan ukuran diameter paku dan jumlah paku maka semakin meningkat pula nilai kapasitas beban ijin total per bidang geser. Untuk melihat seberapa kuat hubungan antara interaksi faktor diameter dan jumlah paku tersebut terhadap nilai RT dilakukan analisa regresi linier sederhana, sebagaimana disajikan pada Gambar 1.

Gambar 1 secara umum memperlihatkan peningkatan nilai perbandingan antara luas penampang paku dengan luas bidang sambungan diikuti pula dengan meningkatnya nilai rataan $\mathrm{RT}$ kayu Nangka. Bentuk matematis yang diperoleh dari hubungan antara perbandingan luas penampang paku dengan luas bidang sambungan $(\mathrm{x}$ ) dengan nilai kapasitas beban ijin total per bidang geser (y) adalah model regresi sederhana $y=1.587,5 x+$ 749,42 dengan nilai $R^{2}=84,38 \%$. Hal ini berarti model di atas dapat menerangkan hubungan yang positip dan cukup erat dimana respon (y) atau nilai RT kayu nangka dapat diduga sebesar $85 \%$ dari variabel bebas $(x)$ atau rasio bidang paku terhadap bidang sambungannya.

\section{Kekuatan Sambungan Geser Ganda Kayu Rasamala}

\section{Kapasitas beban ijin per paku per bidang geser}

Sama halnya dengan kayu Nangka, maka fenomena sebaran kapasitas beban ijin per paku per bidang geser kayu Rasamala (Tabel 3) juga memperlihatkan kecenderungan semakin besar diameter paku yang digunakan maka semakin besar pula nilai kekuatan double shear atau kapasitas beban ijin per paku per bidang geser $(\bar{R})$ kayu tersebut. Namun demikian fenomenanya berbeda menurut jumlah paku, dimana semakin besar jumlah paku yang digunakan justeru terdapat tendensi makin menurun nilai untuk setiap diameter paku walaupun pada pemakaian 10 batang terjadi peningkatan kembali nilai. Namun perbedaan nilai ini tidak begitu signifikan.

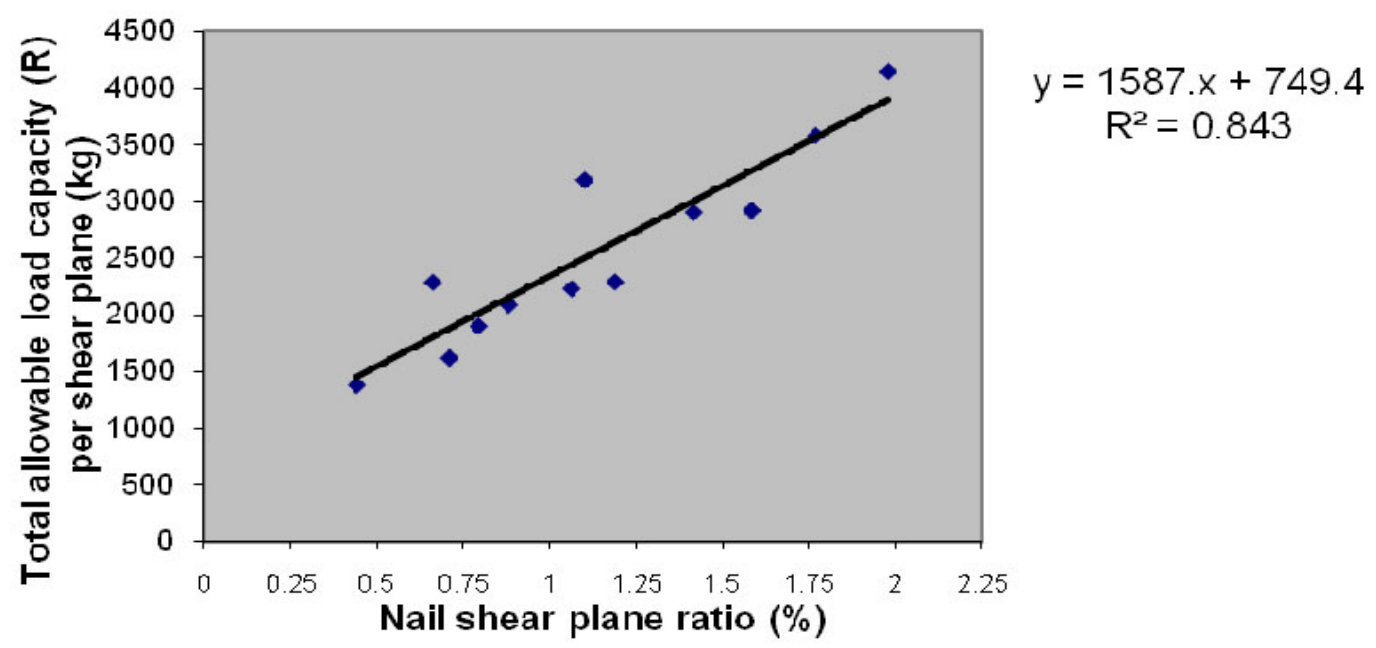

Gambar 1. Hubungan nilai rasio antara diameter dan jumlah paku terhadap nilai RT kayu nangka 
Tabel 3. Nilai rata-rata $\bar{R}$ kayu rasamala berdasarkan diameter dan jumlah paku (kg)

\begin{tabular}{|c|c|c|c|c|c|}
\hline \multirow{2}{*}{$\begin{array}{l}\text { Diameter paku } \\
(\mathrm{mm})\end{array}$} & \multicolumn{4}{|c|}{ Jumlah paku (buah) } & \multirow{2}{*}{ Rata-rata } \\
\hline & 4 & 6 & 8 & 10 & \\
\hline 4,1 & 241 & 227 & 239 & 278 & 246 \\
\hline 5,2 & 390 & 359 & 321 & 311 & 345 \\
\hline 5,5 & 321 & 353 & 360 & 376 & 352 \\
\hline Rata-rata & 317 & 313 & 307 & 322 & \\
\hline
\end{tabular}

Tabel 4. Nilai rata-rata RT kayu rasamala berdasarkan diameter dan jumlah paku (kg)

\begin{tabular}{|c|c|c|c|c|c|}
\hline \multirow{2}{*}{$\begin{array}{l}\text { Diameter paku } \\
\quad(\mathrm{mm})\end{array}$} & \multicolumn{4}{|c|}{ Jumlah paku (buah) } & \multirow{2}{*}{ Rata-rata } \\
\hline & 4 & 6 & 8 & 10 & \\
\hline 4,1 & 962 & 1.359 & 1.912 & 2.785 & 1.754 \\
\hline 5,2 & 1.561 & 2.153 & 2.568 & 3.106 & 2.347 \\
\hline 5,5 & 1.283 & 2.116 & 2.878 & 3.763 & 2.510 \\
\hline Rata-rata & 1.268 & 1.876 & 2.452 & 3.218 & \\
\hline
\end{tabular}

Hasil analisis nilai rataan kayu rasamala pada sesaran $5 \mathrm{~mm}$ menunjukkan bahwa interaksi antara faktor diameter paku dengan jumlah paku memberikan pengaruh nyata terhadap nilai, dimana $F_{\text {hitung }}(37,40)>F_{\text {tabel }}(2,508)$ pada selang kepercayaan $95 \%$ dan $F_{\text {hitung }}(37,40)>F_{\text {tabel }}(3,667)$ pada selang kepercayaan $99 \%$.

Hasil uji lanjut Duncan menunjukkan bahwa perlakuan $A_{2} B_{1}$ (diameter paku $5,2 \mathrm{~mm}$ dengan jumlah paku 4 batang) menghasilkan paling tinggi yaitu dengan nilai $390,2 \mathrm{~kg}$, sedangkan perlakuan $A_{1} B_{2}$ (diameter paku 4,1 mm dengan jumlah paku 6 batang) menghasilkan nilai yang paling rendah yaitu $226,2 \mathrm{~kg}$. Secara umum dapat dilihat bahwa penggunaan paku berdiameter $4,1 \mathrm{~mm}$ menghasilkan nilai yang minimum.

Memperhatikan Tabel 2 dimana nilai minimum untuk setiap ukuran diameter paku berbeda menurut pamakaian jumlah paku. Pada diameter paku terkecil $(4,1 \mathrm{~mm})$ diperoleh minimum saat pemakaian 6 batang paku, dan diameter $5,2 \mathrm{~mm}$ nilai minimum dicapai pada 10 batang paku serta diameter terbesar $5,5 \mathrm{~mm}$ justru minimum dengan hanya 4 paku. Fenomena minimum kayu nangka berbeda dengan minimum yang diperoleh dari kayu rasamala.

\section{Kapasitas beban ijin total per bidang geser}

Sama sepertikayunangka, Tabel 4 menunjukkan bahwa nilai RT kayu rasamalasemakin besar dengan semakin besarnya ukuran diameter dan jumlah paku yang digunakan.

Hasil analisis ragam menunjukkan bahwa interaksi diameter paku dengan jumlah paku memberikan pengaruh yang sangat nyata terhadap nilai kapasitas beban ijin total per bidang geser dimana $F_{\text {hitung }}(22,24)>F_{\text {tabel }}(2,508)$ pada selang kepercayaan $95 \%$ dan $F_{\text {hitung }}(22,24)>F_{\text {tabel }}(3,667)$ pada selang kepercayaan $99 \%$. Sama seperti kayu nangka, Tabel 4 juga menunjukkan bahwa nilai RT kayu rasamala semakin besar dengan semakin besarnya ukuran diameter dan jumlah paku yang digunakan.

Hasil analisis ragam menunjukkan bahwa interaksi diameter paku dengan jumlah paku memberikan pengaruh yang sangat nyata terhadap nilai kapasitas beban ijin total per bidang geser dimana $F_{\text {hitung }}(22,24)>F_{\text {tabel }}(2,508)$ pada selang kepercayaan $95 \%$ dan $F_{\text {hitung }}(22,24)>F_{\text {tabel }}(3,667)$ pada selang kepercayaan $99 \%$.

Perlakuan $\mathrm{A}_{3} \mathrm{~B}_{4}$ (diameter paku 5,5 mm dengan jumlah paku 10 batang) menghasilkan nilai RT paling tinggi yaitu $3.763 \mathrm{~kg}$, sedangkan untuk perlakuan $A_{1} B_{1}$ (diameter paku $4,1 \mathrm{~mm}$ dengan jumlah paku 4 batang) menghasilkan nilai RT paling rendah yaitu $962 \mathrm{~kg}$.

Hasil penelitian seperti ditunjukkan pada Gambar 2 memperlihatkan adanya kecenderungan peningkatan nilai rasio antara luas penampang paku dengan luas bidang sambungan akan meningkatkan nilai rataan kapasitas beban ijin total per bidang geser pada kayu rasamala. Seperti halnya pada kayu nangka, kekuatan sambungan double shear kayu rasamala juga berdasarkan data rata-rata kapasitas beban ijin total per bidang geser yang dihasilkan pada sesaran $5 \mathrm{~mm}$ dapat dirumuskan model matematisnya dari hubungan antara nilai rasio luas penampang paku dengan luas bidang 


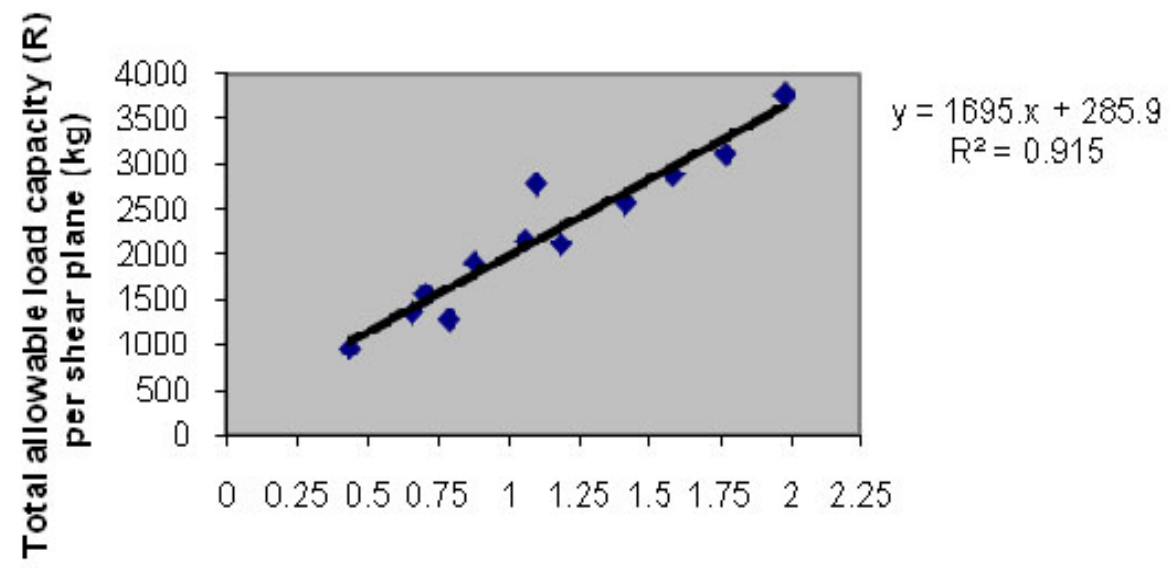

Nail shear plane ratio(\%)

Gambar 2. Hubungan nilai rasio antara diameter dan jumlah paku terhadap nilai RT kayu rasamala

sambungan $(\mathrm{x})$ dengan nilai kapasitas beban ijin total per bidang geser (y). Model sederhana dan terbaik diperoleh melalui model regresi dengan persamaan $y=1695,7 x+285,95$ dengan nilai $R^{2}=91,52 \%$. Hal ini berarti model penduga kayu rasamala sedikit lebih baik dibandingkan kayu nangka dilihat dari besarnya koefisien determinasi kedua persamaan tersebut.

\section{KESIMPULAN}

Kesimpulan yang diperoleh dari hasil penelitian ini adalah sebagai berikut:

1. Peningkatan diameter dan jumlah paku akan meningkatkan kapasitas beban ijin (kekuatan sambungan double shear balok kayu-pelat baja) per paku per bidang geser dan kapasitas beban ijin total per bidang geser pada kayu Nangka (A. heterophyllus) dan atau Rasamala (A. excelsa Noronha).

2. Secara umum pola sebaran kapasitas beban ijin per paku terbesar dan terkecil berbeda menurut diameter dan jumlah paku untuk masingmasing jenis kayu, namun pola sebaran beban totalnya relatif sama untuk semua jenis kayu. Beban total cenderung meningkat dengan meningkatnya ukuran diameter paku (4,1-5,5 $\mathrm{mm}$ ) dan jumlah paku (4-10 batang), namun pada ukuran diameter paku $5,5 \mathrm{~mm}$ beban total sambungan mencapai maksimumnya pada jumlah paku 8 batang, kemudian menurun kembali pada jumlah 10 batang paku.

3. Nilai disain kekuatan sambungan tarik double shear ditetapkan berdasarkan penggandaan dari nilai kapasitas beban ijin per paku terkecil untuk masing-masing diameter paku dengan jumlah paku yang akan digunakan.

\section{DAFTAR PUSTAKA}

Anonim. 2001. Wood Design Manual. Canadian Wood Council. Canada.

Forest Product Society. 1990. Wood Handbook Engineering. Pentice-Hall, Inc. Englewood Cliiffs, New Jersey.

Forest Product Society. 1999. Wood Handbook: Wood as an Engineering Material. USDA Forest Service. Forest Product Laboratory. USA.

Forest Product Society. 2001. Handbook of Wood and WoodBased Materials for Engineers, Architects, and Builders. USDA Forest Service. Forest Product Laboratory. USA.

Foschi, R.O. and T. Bonac. 1977. Load Slip Characteristics for Connections With Common Nails. Journal of Wood Science. Vol.9, No.3.

Martawijaya, A., I. Kartasujana, Y. I. Mandang, S. A. Prawira, and K. Kadir. 1981. Atlas Kayu Indonesia Jilid II. Pusat Penelitian Pengembangan Kehutanan. Bogor.

Murwentianto, B. 2003. Perubahan Sifat Keasaman Kayu Nangka (Arthocarpus heterophyllus Lamk), Manii (Maesopsis eminii) \& Sengon (Paraserianthes falcataria) Selama Proses Pengeringan. [Skripsi]. Bogor: Fakultas Kehutanan, Institut Pertanian Bogor.

Pandit, I.K.N. and H. Ramdan. 2002. Anatomi Kayu: Pengantar Sifat Kayu Sebagai Bahan Baku. Yayasan Penerbit, Fakultas Kehutanan IPB. Bogor.

Pun, C.Y. 1987. Structural Timber Joints. Malayan Forest Record No.32. Forest Research Institut Malaysia. Kuala Lumpur. 
Rita, I. 2007. Keawetan Alami dan Dugaan Perubahan Kekauan Kayu Nangka dan Mangium. [Skripsi]. Bogor: Fakultas Kehutanan, Institut Pertanian Bogor.

Sucahyo, S. and S. Agustina. 2005. Kajian Hubungan antara Kekuatan Sambungan Paku dengan Diameter Paku dan Berat Jenis pada Beberapa Kayu Indonesia. Jurnal IImu dan Teknologi Kayu Tropis. Vol.3, No.1. Masyarakat Peneliti Kayu Indonesia.

Surjokusumo, S. 1984. Penggunaan Panel Kayu Khususnya Kayu Lapis Ditinjau dari Segi Keteknikan. Proceeding Seminar Fokus Kayu Lapis, 84. Jakarta.
Thelandersson, S. and J. L. Hans. 2003. Timber Engineering. John Wiley \& Sons, Ltd. England.

Yap, F.K.H. 1984. Konstruksi Kayu. Bina Cipta. Bandung.

Yeyet. 2008. Pengaruh Diameter dan Jumlah Alat Sambung Paku terhadap Kekuatan Sambungan Tarik Tiga Jenis Kayu dengan Berat Jenis Berbeda. [Skripsi]. Bogor: Fakultas Kehutanan, Institut Pertanian Bogor. 